\title{
Debating Net Neutrality
}

\author{
Advocates seek to protect users from potential business practices, \\ but defenders of the status quo say that concerns are overblown.
}

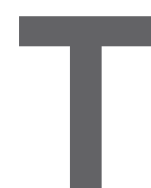

HE CONTROVERSY ABOUT network neutrality-the principle that Internet users should be able to access any Web content or use any applications, without restrictions or limitations from their Internet service provider (ISP) - remains unresolved in the U.S. over who, if anyone, has a legal or commercial right to regulate Internet traffic. Net neutrality proponents advocate for legislation that would keep broadband service providers from controlling Internet content or gaining the ability to impose extra charges for heavy users of the Internet. Opponents argue that existing rules enforced by the Federal Communications Commission (FCC) and others make additional laws unnecessary, or could jeopardize service providers' First Amendment rights.

But now some analysts are warning that the battle may ultimately mean much more than decisions about bits, bandwidth, pricing, and flow control.

"The battle for Net neutrality is also a battle over the shape of American culture," says Tim Wu, a Columbia University law professor specializing in copyrights and communications who wrote a 2003 paper, "Network Neutrality, Broadband Discrimination," which popularized the concept of Net neutrality.

Wu fears that in an under-regulated Internet ruled by ISPs, commercial motives could stifle entertainment, culture, and political diversity. For example, Wu says, the current open Internet is "bad for the business models" of traditional newspapers, many of which don't charge for the news they publish on their Web sites. But what if a news organization, for financial means, aligned itself with an individual ISP to sell premium content?

"If you imagine a non-open Internet, there could be the official newspapers of AT\&T's network, let's say," Wu

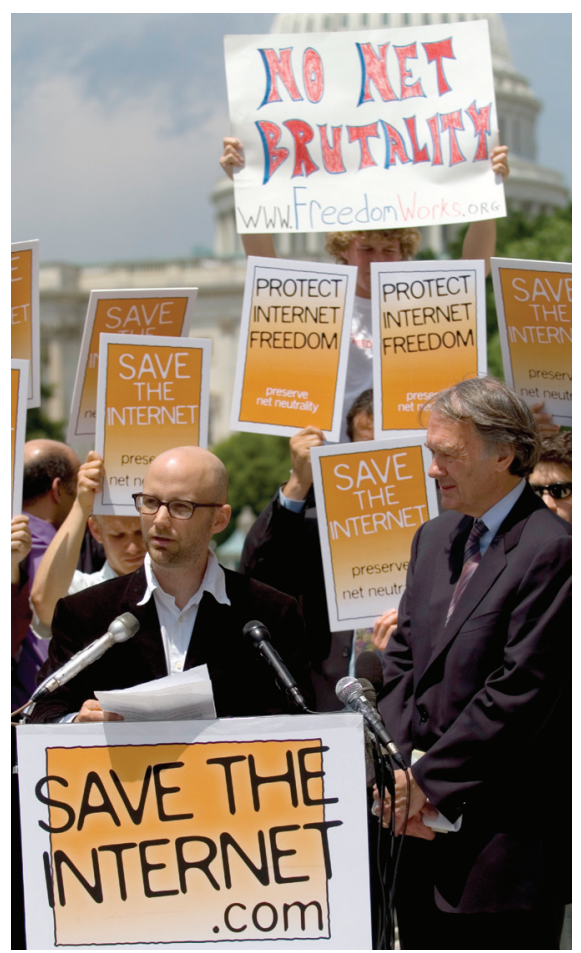

Musical artist Moby, left, and U.S. Representative Ed Markey at a Savethelnternet.com press conference on net neutrality in Washington, D.C., with a counterdemonstrator's sign blocking the view of the Capitol dome.

explains. Part of an AT\&T customer's monthly bill would support the Wall Street Journal, for example, but these subscribers "can't get access to USA Today or something else. It starts to become a little bit dicey when you can see how that would help [news organization's] business models."

Innovation and experimentation could also suffer, Wu warns. "In the early days of mobile phones, the only way an application appeared on a mobile phone was if it made money for the phone company," he says. But in an Internet context, because some now-familiar features don't have a direct commercial bent, they may never have been introduced. "In an Internet that [ISPs] can control, why would you put Wikipedia on it?" he asks. "It doesn't make sense because it doesn't make money."
Vinton Cerf, chief Internet evangelist at Google, also sees potential accessibility problems if broadband providers wield too much power. "All of us, in the consumer space especially, stand to lose the opportunity to access new products and services if we don't get [the debate] right," Cerf warns.

Cerf cites the well-publicized legal wrangling over broadband provider Comcast's deliberate slowing down of traffic for customers using BitTorrent and other filing-sharing applications on its network in 2007. "As long as we have clumsy or consumer-unfriendly regimes for network management," he says, "we will see problems for some reasonable applications and thus some inhibition of innovative new services."

Cerf envisions a safer Net world where regulations would constrain anti-competitive practices, such as unfair pricing by ISPs that compete with providers of online movie-on-demand services. "Fairly high aggregate caps on total monthly transfers or, preferably, a cap on the minimum assured rate for a given price would be very attractive," Cerf says. The "key point," he adds, is that "the user gets to pay for a guarantee of a certain minimum rate. If the user doesn't use it, others may. That's the whole dynamic of capacity sharing."

\section{Net Neutrality Skeptics}

Others dismiss such fears. "The threat level is not red or orange. We are way down in yellow," says Barbara Esbin, director of the Center for Communications and Competition Policy at the Progress and Freedom Foundation, a pro-business Washington, D.C.-based think tank supported in part by broadband providers such as AT\&T, Comcast, and Verizon.

Net neutrality skeptics dismiss the notion that the lack of additional Internet controls is endangering society, and argue that the status quo engenders a 
competitive market that's adequately watched over by the FCC and Federal Trade Commission. The current environment promotes innovation, says Robert Pepper, vice president of global technology policy for Cisco Systems. He cites the ongoing investments in fiber-optic networks for broadband services as well as the move by wireless carriers to provide high-speed $3 \mathrm{G}$ and WiMAX networks. "The whole innovation engine offers numerous examples of new apps being developed, new business models being tried," Pepper says. "Where is the failure to innovate?"

Others go further, saying that new constraints imposed in the name of Net neutrality could make it difficult for service providers to do essential management and maintenance. For example, some Net neutrality advocates worry about ISPs examining not just the headers of the data trafficinformation required for routing it through the network-but also peering into the actual content of the packets. They worry that such deep packet inspections could open the door to blocking of content for commercial or political reasons.

But the danger of deep packet inspection should be kept in perspective, say some experts. For one thing; the technique is important for secure network operation, says David Farber, a professor of computer science and public policy at Carnegie Mellon University. "If I can't do deep packet inspections I have no way as a carrier of handling denial-of-service attacks," he says.

\section{Concerns About Privacy}

Still, issues surrounding Net neutrality could impinge on fundamental concerns about personal privacy. David Clark, a senior research scientist at Massachusetts Institute of Technology, says the danger is more subtle than that of ISPs blatantly snooping on what sort of content is being transmitted through their pipes. Using deeppacket inspections to block content "is nonsense in the United States," says Clark. "That's so 20th century." The more relevant danger, according to Clark, is that ISPs will be motivated by profit opportunities to analyze what content subscribers are viewing and then use that data for commercial gain. "What we are going to be fighting about in two years is who has the right to observe everything you do," he predicts. "[ISPs] can completely model you based on your behavior by doing a deep-packet inspection. That's the issue that takes over from the rather simplistic fear that what these ISPs are going to block a packet or degrade access or something."

One attractive commercial option is for ISPs to replicate the revenue niche established by companies like Google. For example, when an Internet user enters a search query for mortgage rates in Arizona, "that guy is targeted" by search engine companies, Clark points out. These search firms can insert relevant ads into the pages that display query results and charge advertisers a premium for delivering their messages to a highly targeted audience. Various types of analytical applications could give broadband providers an efficient way to slice and dice their customers' usage data, and thus gives ISPs an opportunity to argue that they're able to

\section{"What we are going to be fighting about in two years," says David Clark, "is who has the right to observe everything you do."}

place ads as precisely tuned to individual users' interests as those inserted by search companies. Clark notes that modeling is already happening thanks to companies such as Phorm, which feed ISPs analyses of consumer behavior on the Web.

But existing regulatory and market forces may already be working to keep abuses in check. "I've heard of a few companies in the past that have bought those services," Farber says. "But they usually backed off rapidly because of the noise they were getting" by congressional watchdogs. Indeed, an ad-targeting company similar to Phorm, called NebuAd, shut down its U.S. operation in mid-2009 after becoming the target of congressional scrutiny. That wasn't the final word, however; the company immediately started doing business in England as Insight Ready Ltd.

Alan Joch is a business and technology writer based in Francestown, $\mathrm{NH}$.

(c) 2009 ACM 0001-0782/09/1000 $\$ 10.00$

\section{Net Neutrality: A Worldwide Debate}

\begin{abstract}
Nations around the world are refereeing similar debates although often in the context of a different competitive environment. For example, industry estimates count more than 200 European network operators that provide Internet services. The U.S., by contrast, has only about a dozen large broadband ISPs.

Nevertheless, the two continents may eventually find themselves influencing
\end{abstract}

how the other resolves the Net neutrality debate. In May, the European Parliament voted for a package of telecommunications policies, including one that affirms the principle of Net neutrality. According to The New York Times, groups of U.S. lobbyists were on site to influence European regulations over the winter when the measure was being debated. The goal: any decisions formalized in
Brussels might shape the views of U.S. regulators. One analyst isn't surprised by the outreach by U.S. lobbyists. "Net neutrality is a rainmaker issue-you can get a lot of funding for your organization if you can point to a crisis that requires your group's advocacy to resolve it," says Barbara Esbin, director of the Center for Communications and Competition Policy at the
Progress and Freedom Foundation, a pro-market Washington, D.C.-based think tank.

But Esbin believes the U.S. could ultimately play the most influential role of all. "The U.S. is going to be looked at for how we resolve this," she says, "and it would be great if this country could show leadership again on communications policy." -Alan Joch 